\title{
Article \\ IoT Framework for Measurement and Precision Agriculture: Predicting the Crop Using Machine Learning Algorithms
}

\author{
Kalaiselvi Bakthavatchalam ${ }^{1}$, Balaguru Karthik ${ }^{1}$, Vijayan Thiruvengadam ${ }^{1}$, Sriram Muthal ${ }^{2}$, Deepa Jose ${ }^{3}$,
} Ketan Kotecha ${ }^{4, *(D)}$ and Vijayakumar Varadarajan ${ }^{5, *(\mathbb{D}}$

Citation: Bakthavatchalam, K.; Karthik, B.; Thiruvengadam, V.;

Muthal, S.; Jose, D.; Kotecha, K.; Varadarajan, V. IoT Framework for Measurement and Precision Agriculture: Predicting the Crop Using Machine Learning Algorithms. Technologies 2022, 10, 13. https:// doi.org/10.3390/technologies 10010013

Academic Editor: Pedro Antonio Gutiérrez

Received: 27 November 2021 Accepted: 11 January 2022 Published: 20 January 2022

Publisher's Note: MDPI stays neutral with regard to jurisdictional claims in published maps and institutional affiliations.

Copyright: (C) 2022 by the authors. Licensee MDPI, Basel, Switzerland. This article is an open access article distributed under the terms and conditions of the Creative Commons Attribution (CC BY) license (https:// creativecommons.org/licenses/by/ $4.0 /)$.
1 Department of Electronics and Communication, Bharath Institute of Higher Education and Research, Chennai 600073, India; kalaigopal1973@gmail.com (K.B.); karthikguru33@gmail.com (B.K.); tvij16@gmail.com (V.T.)

2 Department of Computer Science and Engineering, Bharath Institute of Higher Education and Research, Chennai 600073, India; msr1sriram@gmail.com

3 Department of Electronics and Communication Engineering, KCG College of Technology, Chennai 600097, India; deepa.ece@kcgcollege.com

4 Symbiosis Centre for Applied Artificial Intelligence, Symbiosis International (Deemed University), Sena Pati Bapat Road, Pune 411004, India

5 School of Computer Science and Engineering, The University of New SouthWales, Sydney 466, Australia

* Correspondence: head@scaai.siu.edu.in (K.K.); v.varadarajan@unsw.edu.au (V.V.)

\begin{abstract}
IoT architectures facilitate us to generate data for large and remote agriculture areas and the same can be utilized for Crop predictions using this machine learning algorithm. Recommendations are based on the following $\mathrm{N}, \mathrm{P}, \mathrm{K}, \mathrm{pH}$, Temperature, Humidity, and Rainfall these attributes decide the crop to be recommended. The data set has 2200 instances and 8 attributes. Nearly 22 different crops are recommended for a different combination of 8 attributes. Using the supervised learning method, the optimum model is attained using selected machine learning algorithms in WEKA. The Machine learning algorithm selected for classifying is multilayer perceptron rules-based classifier JRip, and decision table classifier. The main objective of this case study is to end up with a model which predicts the high yield crop and precision agriculture. The proposed system modeling incorporates the trending technology, IoT, and Agriculture needy measurements. The performance assessed by the selected classifiers is $98.2273 \%$, the Weighted average Receiver Operator Characteristics is 1 with the maximum time taken to build the model being $8.05 \mathrm{~s}$.
\end{abstract}

Keywords: precision agriculture; WEKA; machine learning; multilayer perceptron; JRip; decision table

\section{Introduction}

India ranks second in the world in farm output but $64 \%$ of cultivated land depends on the monsoons. Irrigation accounts for nearly $85 \%$ of water and nearly $60 \%$ of water is wasted during irrigation. Precision agriculture can be defined as "the application of modern information technologies to provide, process, and analyze multi-source data of high spatial and temporal resolution for decision making and operations in the management of crop production. This Precise agriculture may give rise to enhance productivity, Soil degradation, Efficient water usage, reduction in chemical usage for cultivation, dissemination of modern farm practices to improve quality, quantity, and cost of production in crops. By incorporating Agriculture IoT solutions are focused on helping farmers close the supply-demand gap, by ensuring high yields, profitability, and protection of the environment. The approach of using IoT technology to ensure optimum application of resources to achieve high crop yields and reduce operational costs is called precision agriculture [1-3]. IoT application in Precision Agriculture is focused on crop water management, Pest control and management, Precise detection and nutrients management and safely storing management. 
Historical development of sensors shows the progress in measuring various parameters like temperature, $\mathrm{pH}$, Humidity, Analytical parameters like potassium, phosphorous, Nitrogen measurements from a remote location and the data acquisition is possible to attain all the measurements using sensors thereby the data is stored in the cloud or network server for further processing as shown in Figure 1.

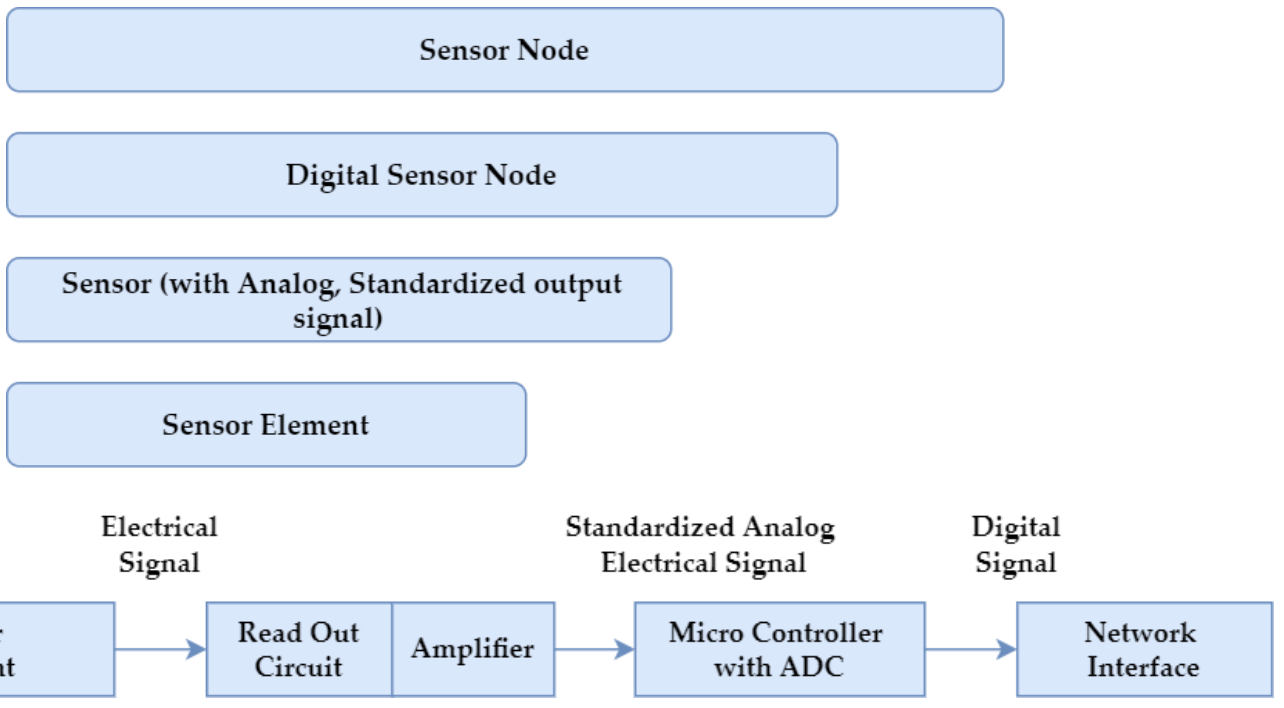

Figure 1. Historical progression of sensors.

Sensors are combined to form a network that can be accessed or linked by cloud/ backend where the sensor responses in a different geographical area are linked by the cloud [4-6]. There are four different phases from smart things without connectivity next progression was a local exchange of information and distributed control systems with programmable logic controllers, the network of things. The next phase includes internetbased communication for monitoring and control, things on the internet. The final phase is regional, global, and open control loops and IoT [7,8]. Examples Seamless internet of things supply chain management and product life cycle management [9-11].

Organization of the paper: The article is composed of five sections and started from strengthening the concept to deploy a module to recommend the crop for irrigation and attain maximum yield with the recommended crop. The next section is related to works from IoT in the Agriculture sector and precision agriculture using machine learning algorithms. This is followed by the methodology, proposed block diagram, and experimental setup. Then the experimental analysis and discussion end with references.

\section{Literature Review}

Machine learning is a major source of technological trending revolutions. With recent developments in the process control industry, expectations on both the client and server sides suggest when recommending specific crops using the Internet, reputable magazine articles, and machine learning algorithms of choice. It is detailed from the available resources, such as the conferences that support the system. Online web journals provide important information and generally provide tips and solutions in the event of a malfunction. It is essential to anticipate such problems and deceptions that can lead to serious consequences of failure. 
M. S. Paroquet et al. (2019) [12] automatic maintaining and monitoring agricultural farms using IoT.S. Al-Sarawi et al. (2017) [13] collection of smart devices exchange data using wireless IoT and communication technologies and protocols using BLE, NFC, LPWAN, LoWPAN. Agrawal et al. (2019) [14] best utilization of technology for farmers through IoT and with some chip, embedded sensors, and smartphone applications farmers can monitor the soil fertility, temperature, rainfall, recommendations on plantation crops. Vadapalli et al. (2020) [15] productivity is based on acquiring data from the sensors using modern electronic gadgets to do smart agriculture using IoT. J. Gubbi et al. (2013) [16] present innovation in IoT using ubiquitous computing web sharing information from all over present sensors sensing enabled by WSN across many areas of modern habitation. $\mathrm{M}$. Stoes et al. (2016) [17] IoT has driven agriculture using separate 3 layer architecture which uses a low power LoRaWAN, the gateways connecting all devices through IoT and the cloud forms the final layer. This article has driven agriculture to the trending techniques in agriculture which is the backbone for forming a sustainable environment for developing countries. Liu et al. (2018) [18] traditional neural network and ARIMA methods are used to predict the temperature with the help of IoT of varying granularities concerning time.

S. Pudumalar et al. (2017) [19] modern farming methodologies is incorporated by research data of soil characteristics, soil types with crop yield data collection. Ensemble model with voting technique using tree category algorithm, CHAID, KNN, and functionbased Naïve Bayes as machine learners to recommend crop. R. Katarya et al. (2020) [20] different approaches using modern methods like to present crop recommender systems using algorithms like Similarity-based models, Ensemble-based models, neural networks, KNN are used. Parameters chosen are meteorological data, temperature and soil profile and texture has given the best crop recommendations. Laurens Klerkx et al. (2019) [21] 5 thematic clusters are declared like digitization of farming, digitizing skills and farm work, ethics consideration in agriculture production systems, knowledge and innovation systems implementation in agriculture. Value chain maintenance against economics and for managing digitized agriculture. Future research agenda was suggested for smart farming and Agriculture4.0. Shadrin et al. (2019) [22] AI-enabled monitoring system for predicting the growth dynamics of plant leaves. Embedded system incorporated with low-powered sensors, GPU which runs NN based AI System. RNN cum LSTM is the core of the AI system whose operation is guaranteed for 180 days using a Li-ion battery. Kumar et al. (2018) [23] integrated information technology in Agriculture, WSN plays a vital role in data collection, monitoring, and analyzing the data from the agricultural field. The result establishes that crop productivity and quality have greatly improved. The article has surveyed the effect of wireless sensor networks for remote monitoring of the crop.

Tanha Talaviya et al. (2020) [24] revolution in Agriculture is by the implementation of AI for irrigation, weeding, fertilizing with the help of sensor networks and Drone i.e., unmanned aerial vehicles. The outcomes have proven that productivity cum quality has improved, this article is also a survey report by various researchers giving automation in agriculture in recent trends using Drones for spraying and monitoring. Anitha, P. et al. (2018) [25] Agriculture done by predicting before the occurrence anticipatory control using a feed-forward algorithm and ANN in yield predictions. P. Rekha et al. (2017) [26] a primitive method for irrigation, fertilization that leads to a decrease in crop yield eventually less income for farmers. IoT framework helped farmers to improvise their yield cum income. RF and WSN including sensor networks are used to transmit and receive data, optimum usage of fertilizers, monitoring the crop round the clock by using an android mobile application to predict the weather forecast. Rehman et al. (2020) [27] All agricultural activities that depend on environmental parameters like soil conditions, temperature, moisture are all predicted using machine learning algorithms Like the Instance-based KNN algorithm, ANN/ MLP, and RBF are used for IoT based smart Farming. P. K. Priya et al. (2019) [28], Precise crop at right time is done by deep learning algorithm such as ANN. Crop prediction is made using Deep Neural Network and GUI by giving inputs like moisture, temperature, $\mathrm{pH}$, and humidity using sensor network and IoT. Crop suggestions 
help greatly help farmers to decide crops for cultivation. H. B. Biradar et al. (2019) [29] estimating the crop water requirement and incorporating IoT, Cloud computing, and CPSCyber-physical systems which plays a vital role in improving productivity, feeding the world, and preventing starvation. Ravesa Akhter et al. (2021) [30] this article summarizes the latest trend in interfacing the IoT, Wireless sensor networks, data mining cum analytics, and Machine learning in agriculture. Smart agriculture is the trending technology, and this article mainly predicts the apple disease in apple orchards in Kashmir valley using machine learning (simple regression model) and IOT Data analytics. Archana Gupta et al. (2021) [31] this article gives sound knowledge about smart farming using machine learning what crop will give maximum yield depending upon the environmental and sensor network parameters. IoT-based smart farming improvising the entire agriculture sector and increasing the crop productivity, recommend the crop which will give real-time monitoring on the parameters to give maximum productivity and quality. Vivekanandhan et al. (2021) [32] this article influences the feature selection, preprocessing and followed by classification using fuzzy rule-based to validate the input parameters and predict the environmental changes efficiently and attain smart irrigation.

Table 1 describes the comparison of existing IoT framework in agriculture, this related works support to implement in the proposed work.

Table 1. Comparison for existing IoT framework for Agriculture.

\begin{tabular}{|c|c|c|}
\hline Reference & Influence & Outcomes \\
\hline M. S. Farooq et al., 2019 [12] & $\begin{array}{l}\text { They present IoT based Crop } \\
\text { monitoring and smart farming } \\
\text { using Machine learning and } \\
\text { wireless network for } \\
\text { agriculture monitoring }\end{array}$ & $\begin{array}{l}\text { Increased crop yield and data } \\
\text { mining shows timely safe } \\
\text { measure prediction }\end{array}$ \\
\hline S.Al-Sahrawi et al., 2017 [13] & $\begin{array}{l}\text { They present the best wireless } \\
\text { communication protocols } \\
\text { used for IoT }\end{array}$ & $\begin{array}{l}\text { Wireless Personal Area } \\
\text { Networks (6LoWPAN), } \\
\text { ZigBee, Bluetooth Low Energy } \\
\text { (BLE), Z-Wave, and Near Field } \\
\text { Communication (NFC). } \\
\text { convenient for smart farming }\end{array}$ \\
\hline Agrawal et al., 2019 [14] & $\begin{array}{l}\text { The futuristic approach in } \\
\text { collecting data relevant to } \\
\text { agriculture and proposal for } \\
\text { smart agriculture }\end{array}$ & $\begin{array}{l}\text { Sensor and cameras were } \\
\text { installed to monitor the crop } \\
\text { and eventually predict } \\
\text { crop-related problems }\end{array}$ \\
\hline Vadapalli et al., 2019 [15] & $\begin{array}{l}\text { Smart agriculture in precision } \\
\text { farming and linking electronic } \\
\text { gadgets like Arduino, } \\
\text { IoT, Wifi }\end{array}$ & $\begin{array}{l}\text { Uplifting the deteriorating } \\
\text { agriculture sector, } \\
\text { incorporating IoI and Wifi, } \\
\text { Smart farming }\end{array}$ \\
\hline H. Agrawal et al., 2019 [14] & $\begin{array}{l}\text { Energy-constrained devices } \\
\text { and to maintain sensors and } \\
\text { gateway modules. }\end{array}$ & $\begin{array}{l}\text { IoT enabled precision } \\
\text { agriculture and Duty cycle } \\
\text { algorithm for residual } \\
\text { energy parameters. }\end{array}$ \\
\hline Gubbi, J.; et al., 2019 [16] & $\begin{array}{l}\text { IoT enabled smart } \\
\text { sensing system }\end{array}$ & $\begin{array}{l}\text { Microcontroller based Direct } \\
\text { Digital Synthesis } \\
\text { (DDS) method }\end{array}$ \\
\hline Lavanya et al., 2020 [5] & $\begin{array}{l}\text { Novel NPK sensors and IOT } \\
\text { based design }\end{array}$ & $\begin{array}{l}\text { This resulted in high yield } \\
\text { crops and proved helpful } \\
\text { for farmers }\end{array}$ \\
\hline Lavanya et al., 2020 [5] & $\begin{array}{l}\text { IoT based low-cost fertilizer } \\
\text { intimation system }\end{array}$ & $\begin{array}{l}\text { The concept of fuzzy logic is } \\
\text { applied to detect the } \\
\text { deficiency of nutrients from } \\
\text { the sensed data... }\end{array}$ \\
\hline
\end{tabular}




\section{Methodology}

The terms/materials used for this experiment are described for the sake of improving the readability of the proposed framework with clarity.

\subsection{IoT Framework for Agriculture}

The proposed system consists of interfacing the real-world data from storage media to cloud Database management system from where the request is sent to the Machine learning trained model as shown in Figure 2. The output of the module is one among 22 different crops for implementation as shown in Figure 3.

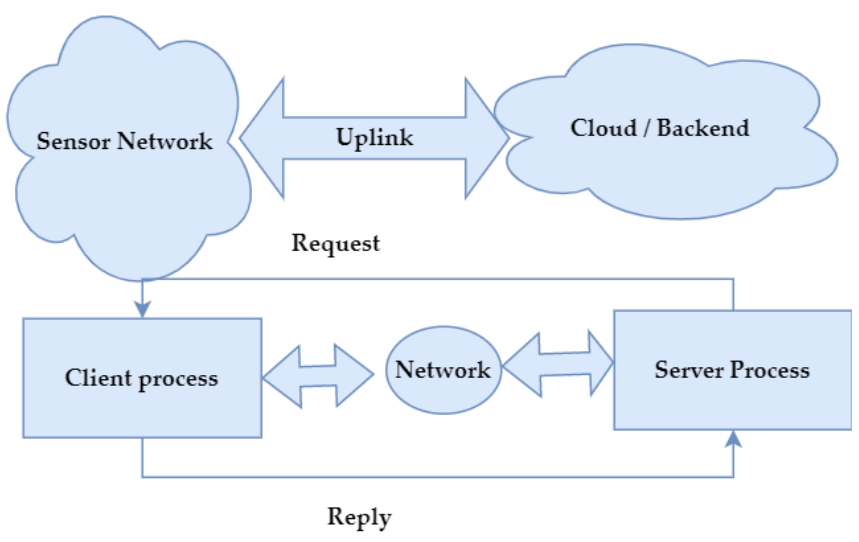

Figure 2. Proposed IoT Client-Server Model.

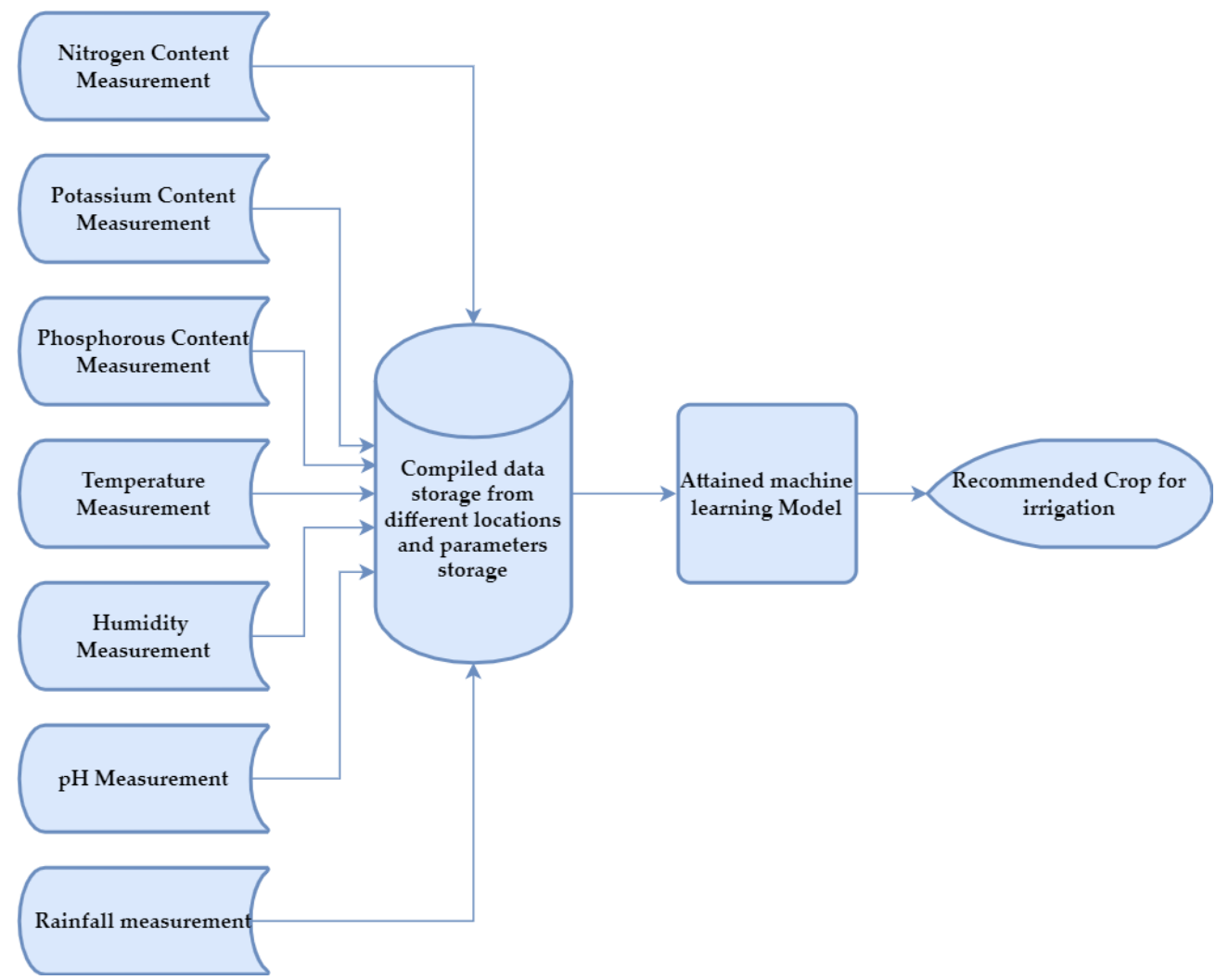

Figure 3. Block diagram using Machine learning Module. 


\subsection{Data Mining and Network Implementation}

Data capturing and communication utilities are enabled in the first level of architecture. The sensor network is linked with the gateway and the base station. In the second level, the classification specification and algorithm module are incorporated. The next level is implementing the ML algorithms to acquire the results from the server. The server has a trained module for getting the specific crop for irrigation. The parameters like Nitrogen, Phosphorous, Potassium, $\mathrm{pH}$ are measured using analytical sensors and stored in the module, Parameters like temperature, Humidity, and rainfall are measured using specific sensors and stored in the database. The compiled data is stored in a spreadsheet with the ground truth by having knowledge about the specified 22 different crops as shown in Figure 3. By training the module using a machine learning algorithm the attained model is ready to recommend the crop for the user for irrigation.Figure 4 shows flow procedure of IoT-based smart agriculture is possible by combining field Physical structure Data acquisition, Data processing, Data analytics for monitoring and control. The datasheet was acquired from Kaggle [33]. on a crop, the recommendation is taken for predicting the crop for irrigation and obtaining maximum yield.

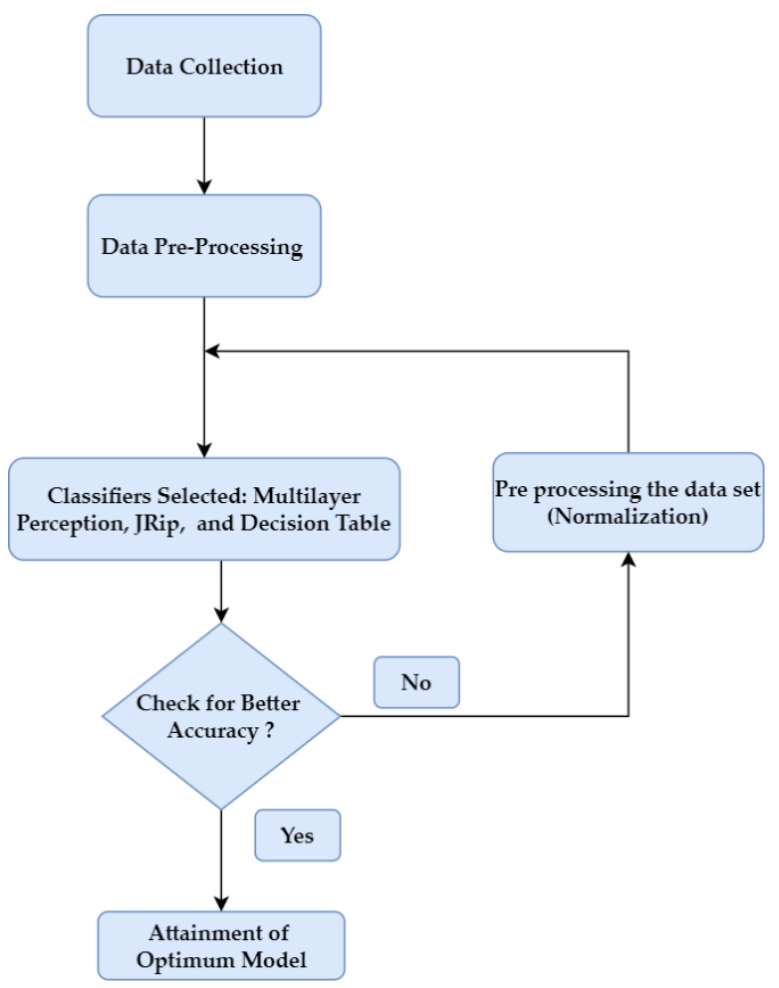

Figure 4. Modelling of crop recommended module set up.

Irrigation of crops depends on different environmental factors and soil fertility i.e., available nutrients present in the soil like nitrogen, phosphorous, and Humidity. The 7 attributes can decide a crop for irrigation so that maximum yield can be attained. This article can be used to make a strong decision making in planting different crops. WEKA or Waikato Environment for Knowledge Analysis the University of Waikato Hamilton, New Zealand is an open-supply facts mining software program issued beneath GNU public license software program that gives freedom to its customers in appearing most of these facts mining works [34].

It is a set of many devices gaining knowledge of algorithms for facts mining tasks. It is a percent of a device that includes diverse operations known as file preparation, clustering, regression, facts preprocessing, classification, Association rules, instance-primarily based totally classifying, and picturing. The technique worried in organizing the project is done 
the use of this software program known as WEKA for modeling the above stated clever positioning the use of photo processing.

\subsection{Selected Classifiers (Supervised Learning Algorithms)}

Some of the selected classifiers are for this module are Multilayer perceptron, JRip, Decision table in tree category are chosen.

\subsubsection{Multilayer Perceptron}

It is also called a supplement of a Feedforward neural network. MLP is composed of three layers namely the input layer, hidden layer, and output layer. MLP has a unique ability to approximate continuous functions rather than only linear functions. MLP is composed of neurons which are also called perceptions. For example, the input receives $n$ features [4] as input $\left(x=x_{1}+x_{2}+x_{3}+x_{4}+x_{5} \ldots \ldots x_{n}\right)$.

These $n$ features are passed on to an input function $u$ that computes the weighted sum for the input layer

$$
U_{(x)}=\sum_{i=1}^{n} w_{i} x_{i} .
$$

This result is passed on to the activation function $\{\mathrm{f}\}$ in this article it is supposed to sigmoid node 0 to sigmoid node 35. MLP has one or more hidden layers. But the input layer and the output layer are exposed to the external world.

\subsubsection{Decision Table}

Rule-based classifier which uses a simple decision table for classification. This classifier consists of the hierarchical table whose entries are broken down by the values of a pair of added features to form another table. This is analogous to dimensional stacking.

\subsubsection{JRip}

This classifier in the WEKA tool is a class-based prepositional rule learner, Repeated Incremental Pruning to Produce Error Reduction (RIPPER). There are two basic phases that are grown phase and the pruning phase. Ingrow phase is the rule by greedily adding highest information gain: $\mathrm{p}(\log (\mathrm{p} / \mathrm{t})-\log (\mathrm{P} / \mathrm{T}))$. In the pruning phase, any final sequences are added to the growing phase. Optimization stage and fixation of discretion length and the whole ruleset is fixed.

\section{Data Preparation Cum Generation}

The dataset used for our experimental analysis is taken from a public repository known to be the Kaggle database [33]. Table 2 is the lookup format for crop recommended dataset with seven different parameters like Nitrogen, potassium, phosphorous, $\mathrm{pH}$, Rainfall, Temperature, and Humidity. The different combinations of these seven parameters give rise to different crops. In the given lookup table defines the crops recommended with the numerical values of the 7 different parameters.

The Kaggle data set contains 2200 instances for 22 different crops as mentioned in the look-up table. The comma-delimited format is used for training the optimum model used supervised learning methods with the selected functions and rule-based classifiers.

\section{Tools Applied}

WEKA (Waikato Environment for Knowledge Analysis) is selected for machine learning algorithm implementation for crop recommendation in this experimental analysis. WEKA is an open-source innovative tool for all research communities working on both supervised and unsupervised learning methodologies. WEKA with java platform implementation is the best-suited tool for machine learning techniques [34]. 
Table 2. Lookup table for crop recommendation with numeric data.

\begin{tabular}{cccc}
\hline S. No & No of Parameters & Instances Count & Crop Recommended \\
\hline 1 & 7 & 100 & Rice \\
2 & 7 & 100 & Maize \\
3 & 7 & 100 & chickpea \\
4 & 7 & 100 & Kidney beans \\
5 & 7 & 100 & Pigeon peas \\
6 & 7 & 100 & Moth beans \\
7 & 7 & 100 & Mung bean \\
8 & 7 & 100 & Black gram \\
9 & 7 & 100 & lentil \\
10 & 7 & 100 & pomegranate \\
11 & 7 & 100 & Banana \\
12 & 7 & 100 & Mango \\
13 & 7 & 100 & Grapes \\
14 & 7 & 100 & Watermelon \\
15 & 7 & 100 & Muskmelon \\
16 & 7 & 100 & apple \\
17 & 7 & 100 & orange \\
18 & 7 & 100 & Papaya \\
19 & 7 & 100 & Coconut \\
20 & 7 & 100 & Cotton \\
21 & 7 & 100 & jute \\
22 & 7 & 100 & coffee \\
& & 2200 & \\
\hline
\end{tabular}

\section{Experimental Results and Discussion}

Data collection is done first and then the dataset format to comma delimited excel format (CSV file) which is compatible for using to train the data set in WEKA tool using supervised learning methods and after completing the preprocessing the classification process is done for the selected classifiers and the performance characteristics are noted and tabulated. By using the preprocessing method of nominal to binary attribute selection will reduce the time taken to build the model.

The results show in Table 3, the classification or the crop recommendation by this optimum model is very well predicted based on the data set and 7 different attributes. The three classifiers namely function-based and rules-based are taken for implementing the machine learning technique had given us an accuracy performance percentage of $98.2273 \%$ to $88.5909 \%$ for multilayer perceptron and JRip classifier as shown in Figure 5. The receiver operator characteristics of 0.991 to 0.997 for the Lazy category classifier decision table and multilayer perceptron.

Table 3. Investigational outcomes of the first iterated model.

\begin{tabular}{ccccccc}
\hline S. No & Category & $\begin{array}{c}\text { Selected WEKA } \\
\text { Classifier }\end{array}$ & $\begin{array}{c}\text { Correctly } \\
\text { Classified } \\
\text { Instances (\%) }\end{array}$ & $\begin{array}{c}\text { Weighted Avg. } \\
\text { ROC }\end{array}$ & $\begin{array}{c}\text { Time to Build } \\
\text { the Model }\end{array}$ & $\begin{array}{c}\text { Analysis } \\
\text { Kappa statistic } \\
0.9814\end{array}$ \\
\hline 1 & Functions & MLP & 98.2273 & 0.997 & 0.56 & $\begin{array}{c}\text { Mean absolute } \\
\text { error } 0.004\end{array}$ \\
\hline 2 & Lazy & Decision table & 88.5909 & 0.991 & 0.58 & $\begin{array}{r}\text { Root mean squared } \\
\text { error } 0.035\end{array}$ \\
\hline 3 & Lazy & JRip & 96.2273 & 0.993 & & 0.23 \\
\hline
\end{tabular}




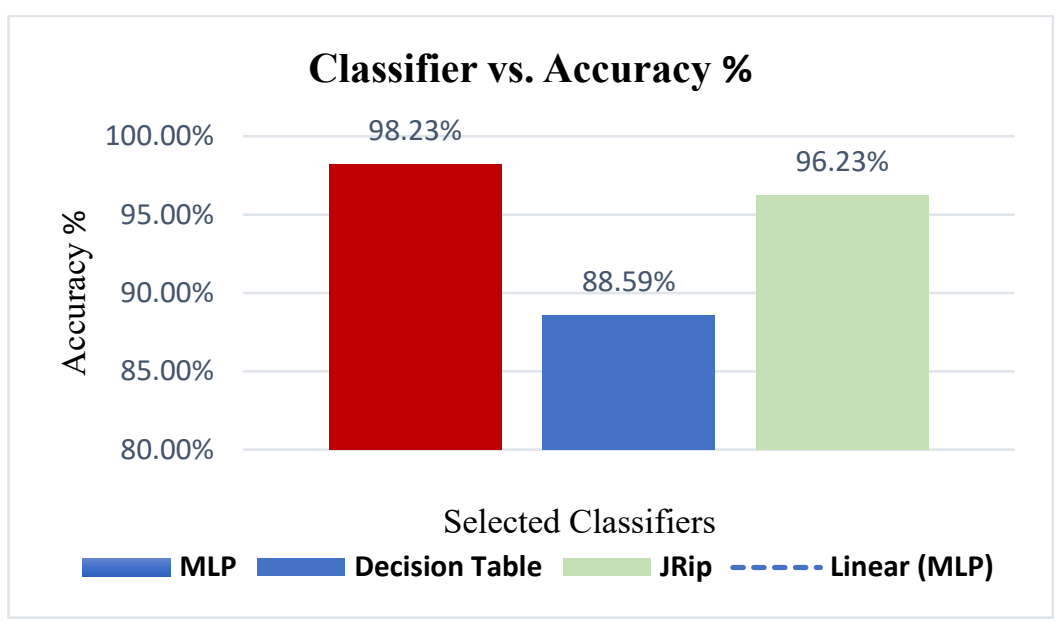

Figure 5. Classifier versus Performance accuracy percentage characteristics.

The performance of the three classifiers namely multilayer perceptron, decision table, and JRip has shown very minimum error and RMSE Error in the range of 0.1384 to 0.058 .

The next characteristics in building the model weighted receiver operator characteristics of 1 will give us an optimum model and MLP showing the best ROC than the selected classifiers as show in Figure 6. The time taken to build the model is spanned from 10.56 to $0.23 \mathrm{~s}$ for multilayer perceptron and decision table classifiers.

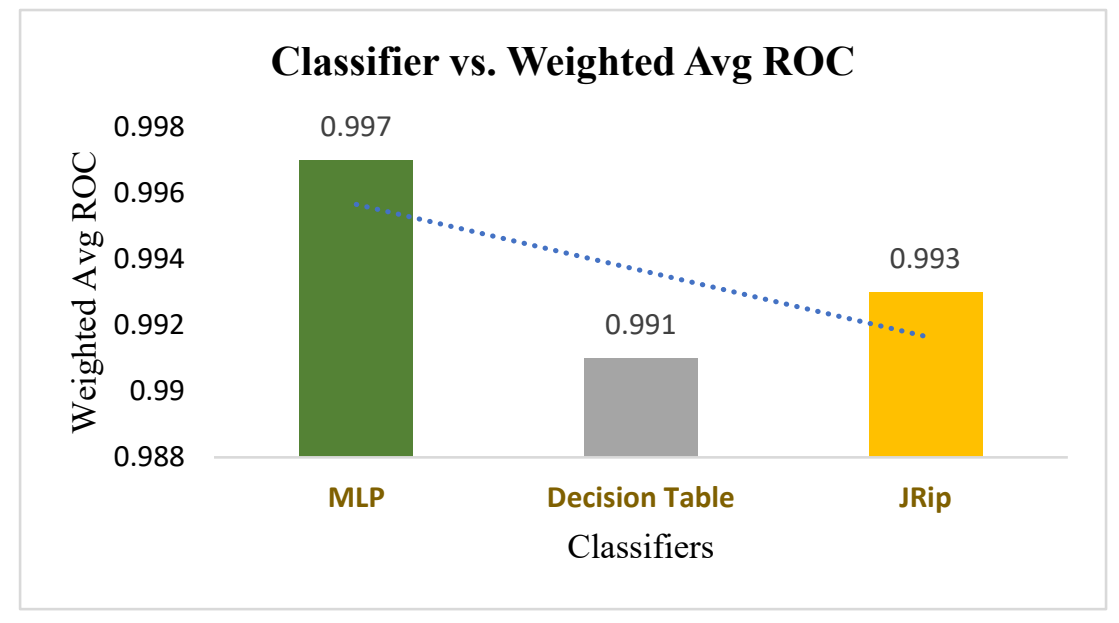

Figure 6. Classifier versus Receiver Operator characteristics.

The preprocessing of the data set by normalization leads to time reduction in building the model and improving the ROC measure to one almost all classifiers show the same measure approximately. The performance of the model has given an accuracy percentage of $98.2273 \%$ for multilayer perceptron and $88.59 \%$ for Lazy category decision table classifier.

The second iterated model clearly dictates that the time taken to build the model is reduced by preprocessing the data set using normalization as shown in Table 4 . The iterated model after pre-processing indicates that the accuracy performance did not vary even after normalizing the data set. But the time to build the model greatly changed. The data set is normalized to reduce redundancy and to get the required result in less time [4]. 
Table 4. Investigational outcome of the second iterated model using Nominalization.

\begin{tabular}{cccccc}
\hline S. No & Category & $\begin{array}{c}\text { Selected WEKA } \\
\text { Classifier }\end{array}$ & $\begin{array}{c}\text { Correctly Classified } \\
\text { Instances (\%) }\end{array}$ & Weighted Avg. ROC & $\begin{array}{c}\text { Time to Build the } \\
\text { Model }\end{array}$ \\
\hline 1 & Functions & MLP & 98.2273 & 1 & 8.78 \\
2 & Lazy & Decision Table & 88.5909 & 0.993 & 0.24 \\
3 & Lazy & JRip & 96.0 & 0.990 & 0.15 \\
\hline
\end{tabular}

Figure 7 shows the accuracy percentage is $98.22 \%$ for MLP and $96 \%$ for JRip after the normalization of data has not deviated from the result. The two iterated model characteristics clearly show that the performance accuracy has not varied. Figure 8 shows the variations in building.

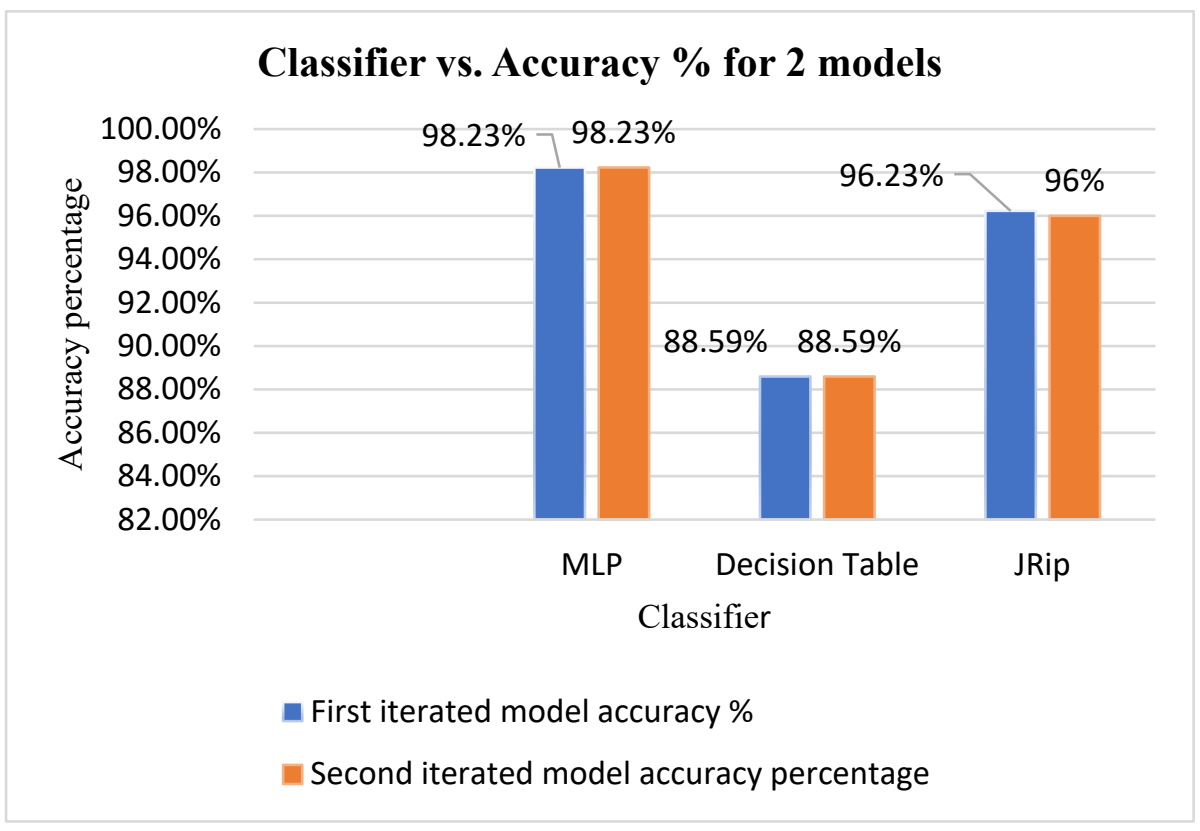

Figure 7. Classifier versus Performance accuracy percentage characteristics.

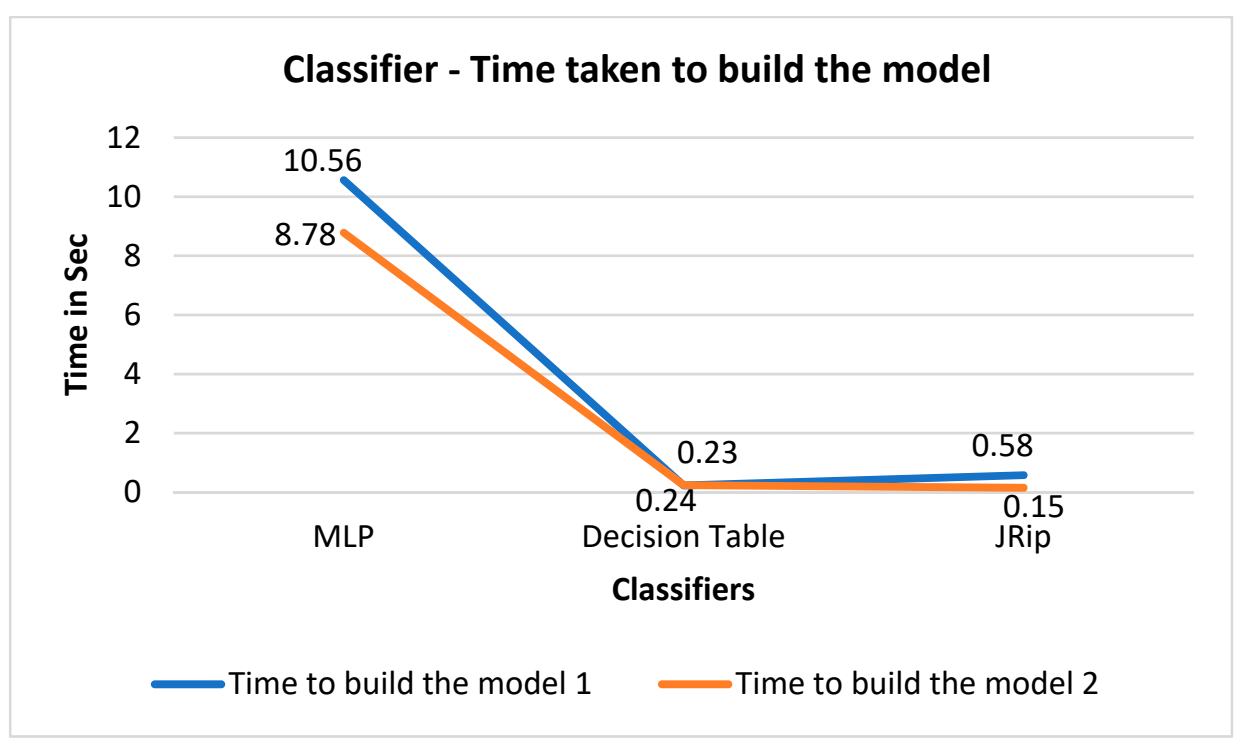

Figure 8. Classifier versus time taken to build model 1 and model 2. 


\section{Conclusions and Future Scope}

Currently, this article is a smart module in recommending the crop for irrigation and obtaining maximum yield based on present environmental factors. This also serves as a guide for any unknown person who is in need of any crop recommendations than facing any trial basis error. The trending machine learning algorithm has helped us to build a model in the agriculture sector also using IoT and helping the farmers in deciding the best yield crop by just measuring the needy parameter like Nitrogen, Phosphorous, Potassium, Rainfall, Temperature, $\mathrm{pH}$, and humidity. In near future, the agriculture sector will be converted into smart agriculture and will never face any decline in production, yield, and quality thereby the agriculture sector progress to AI, IoT-based Precision farming.

Author Contributions: Conceptualization, K.B. and V.T.; methodology, B.K.; software, V.T. and S.M.; validation, K.B., D.J. and K.K.; formal analysis, V.V.; investigation, V.V.; resources, D.J.; data curation, K.B. and S.M.; writing—original draft preparation, V.T.; writing—review and editing, D.J.; visualization, K.K.; supervision, D.J. All authors have read and agreed to the published version of the manuscript.

Funding: No funding for this Research Manuscript.

Institutional Review Board Statement: Not applicable.

Informed Consent Statement: Not applicable.

Data Availability Statement: Data collected from public data base. (www.kaggle.com, 20 November 2021).

Conflicts of Interest: The authors declare no conflict of interest.

\section{References}

1. Ray, P.P. Internet of Things for smart agriculture: Technologies practices and future direction. J. Ambient. Intell. Smart Environ. 2017, 9, 395-420. [CrossRef]

2. Kamienski, C.; Soininen, J.-P.; Taumberger, M.; Dantas, R.; Toscano, A.; Salmon Cinotti, T.; Filev Maia, R.; Torre Neto, A. Smart Water Management Platform: IoT-Based Precision Irrigation for Agriculture. Sensors 2019, 19, 276. [CrossRef] [PubMed]

3. Ojha, T.; Misra, S.; Raghuwanshi, N.S. Wireless sensor networks for agriculture: The state-of-the-art in practice and future challenges. Comput. Electron. Agric. 2015, 118, 66-84. [CrossRef]

4. Vijayan, T.; Sangeetha, M.; Kumaravel, A.; Karthik, B. Feature selection for Simple Color Histogram Filter based on Retinal Fundus Images for Diabetic Retinopathy recognition. IETE J. Res. 2020, 1-8. [CrossRef]

5. Lavanya, G.; Rani, C.; GaneshKumar, P. An automated low cost IoT based Fertilizer Intimation System for smart agriculture. Sustain. Comput. Inform. Syst. 2020, 28, 100300.

6. Sivakumar, M.; Renuka, P.; Chitra, P.; Karthikeyan, S. IoT incorporated deep learning model combined with SmartBin technology for real-time solid waste management. Comput. Intell. 2021. [CrossRef]

7. Katarya, R.; Raturi, A.; Mehndiratta, A.; Thapper, A. Impact of Machine Learning Techniques in Precision Agriculture. In Proceedings of the 2020, 3rd International Conference on Emerging Technologies in Computer Engineering: Machine Learning and Internet of Things, ICETCE, Jaipur, India, 7-8 February 2020; pp. 1-6. [CrossRef]

8. Anitha, P.; Chakravarthy, T. Agricultural Crop Yield Prediction using Artificial Neural Network with Feed Forward Algorithm. Int. J. Comput. Sci. Eng. 2018, 6, 178-181. [CrossRef]

9. Anand, R.; Karthiga, R.D.; Jeevitha, T.; Mithra, J.L.; Yuvaraj, S. Blockchain-Based Agriculture Assistance. Lect. Notes Electr. Eng. 2021, 700, 477. [CrossRef]

10. Prasath, J.S.; Jayakumar, S.; Karthikeyan, K. Real-time implementation for secure monitoring of wastewater treatment plants using internet of things. Int. J. Innov. Technol. Explor. Eng. 2019, 9, 2997-3002. [CrossRef]

11. Anuradha, T.; Ramya, K.; Selvam, R. Design and implementation of solar-powered automatic pesticide sprayer for agriculture. J. Phys. Conf. Ser. 2019, 1362, 12048. [CrossRef]

12. Farooq, M.S.; Riaz, S.; Abid, A.; Abid, K.; Naeem, M.A. A Survey on the Role of IoT in Agriculture for the Implementation of Smart Farming. IEEE Access 2019, 7, 156237-156271. [CrossRef]

13. Al-Sarawi, S.; Anbar, M.; Alieyan, K.; Alzubaidi, M. Internet of Things (IoT) communication protocols: Review. In Proceedings of the 8th International Conference on Information Technology (ICIT), Singapore, 27-29 December 2017; pp. 685-690. [CrossRef]

14. Agrawal, K. Smart Agriculture Using IOT: A Futuristic Approach. Int. J. Inf. Dissem. Technol. 2019, 9, 186. [CrossRef]

15. Vadapalli, A.; Peravali, S.; Dadi, V. Smart Agriculture System using IoT Technology. Int. J. Adv. Res. Sci. Eng. 2019, 9, 58-65.

16. Gubbi, J.; Buyya, R.; Marusic, S.; Palaniswami, M. Internet of Things (IoT): A vision architectural elements and future directions. Future Gener. Comput. Syst. 2013, 29, 1645-1660. [CrossRef] 
17. Stoes, M.; Vank, J.; Masner, J.; Pavlik, J. Internet of Things (IoT) in agriculture-selected aspects. Agris On-Line Pap. Econ. Inform. 2016, 8, 83-88. [CrossRef]

18. Liu, X.; Zhang, C.; Zhang, P.; Yan, M.; Yan, B.; Zhang, J.; Higgs, R. Application of temperature prediction based on neural network in intrusion detection of IoT. Secur. Commun. Netw. 2018, 2018, 1635081. [CrossRef]

19. Pudumalar, S.; Ramanujam, E.; Rajashree, R.H.; Kavya, C.; Kiruthika, T.; Nisha, J. Crop recommendation system for precision agriculture. In Proceedings of the 2016 Eighth International Conference on Advanced Computing (ICoAC), Chennai, India, 19-21 January 2017; pp. 32-36. [CrossRef]

20. Kamienski, C.; Jentsch, M.; Eisenhauer, M.; Kiljander, J.; Ferrera, E.; Rosengren, P.; Thestrup, J.; Souto, E.; Andrade, W.; Sadok, D. Application Development for the Internet of Things: A Context-Aware Mixed Criticality Systems Development Platform. Comput. Commun. 2017, 104, 1-16. [CrossRef]

21. Klerkx, L.; Jakku, E.; Labarthe, P. A review of social science on digital agriculture, smart farming and agriculture 4.0. New contributions and a future research agenda, NJAS-Wageningen. J. Life Sci. 2019, 90, 100315. [CrossRef]

22. Shadrin, D.; Menshchikov, A.; Somov, A.; Bornemann, G.; Hauslage, J.; Fedorov, M. Enabling Precision Agriculture Through Embedded Sensing With Artificial Intelligence. IEEE Trans. Instrum. Meas. 2019, 69, 4103-4113. [CrossRef]

23. Kumar, S.A.; Ilango, P. The Impact of Wireless Sensor Network in the Field of Precision Agriculture: A Review. Wirel. Pers. Commun. 2018, 98, 685-698. [CrossRef]

24. Talaviya, T.; Shah, D.; Patel, N.; Yagnik, H.; Shah, M. Implementation of artificial intelligence in agriculture for optimization of irrigation and application of pesticides and herbicides. Artif. Intell. Agric. 2020, 4, 58-73. [CrossRef]

25. Kamilaris, A.; Gao, F.; Prenafeta-Boldu, F.X.; Ali, M.I. Agri-IoT: A semantic framework for Internet of Things-enabled smart farming applications. In Proceedings of the 2016 IEEE 3rd World Forum on Internet of Things (WF-IoT), Reston, VA, USA, 12-14 December 2016. [CrossRef]

26. Rekha, P.; Rangan, V.P.; Ramesh, M.V.; Nibi, K.V. High yield groundnut agronomy: An IoT based precision farming framework. In Proceedings of the 2017 IEEE Global Humanitarian Technology Conference (GHTC), San Jose, CA, USA, 19-22 October 2017; pp. 1-5. [CrossRef]

27. Rehman, A.; Liu, J.; Li, K.; Mateen, A.; Yasin, Q. Machine Learning Prediction Analysis using IoT for Smart Farming. Int. J. Emerg. Trends Eng. Res. 2020, 8, 1-30. [CrossRef]

28. Priya, P.K.; Yuvaraj, N. An IoT Based Gradient Descent Approach for Precision Crop Suggestion using MLP. J. Phys. Conf. Ser. 2019, 1362, 012038. [CrossRef]

29. Biradar, H.B.; Shabadi, L. Review on IOT based multidisciplinary models for smart farming. In Proceedings of the 2017 2nd IEEE International Conference on Recent Trends in Electronics, Information \& Communication Technology (RTEICT), Bangalore, India, 19-20 May 2017; pp. 1923-1926. [CrossRef]

30. Akhter, R.; Sofi, S.A. Precision agriculture using IoT data analytics and machine learning. J. King Saud Univ.-Comput. Inf. Sci. 2021. [CrossRef]

31. Gupta, A.; Nagda, D.; Nikhare, P.; Sandbhor, A. Smart Crop Prediction using IoT and Machine Learning. IJERT 2021, 9, 18-21.

32. Vivekanandhan, V.R.; Sakthivel, S.; Manikandan, M. Adaptive neuro fuzzy inference system to enhance the classification performance in smart irrigation system. Comput. Intell. 2021. [CrossRef]

33. Available online: https://www.kaggle.com/atharvaingle/crop-recommendation-dataset (accessed on 8 September 2021).

34. Available online: https://www.cs.waikato.ac.nz/ml/WEKA/ (accessed on 6 October 2021). 